\title{
DETERMINATION OF RESEARCH TRENDS IN COVID-19 LITERATURE USING TOPIC MODEL APPROACH
}

\author{
Eda Sonmez and Keziban Seckin Codal \\ Ankara Yildirim Beyazit University, Department of Management Information Systems \\ Ankara Yıldırım Beyazıt University Business School, Building B, Esenboga Campus, 06760 Ankara, Turkey
}

\begin{abstract}
The world is currently facing a significant global health crisis that threatens millions of lives. Researchers and scholars have united to create a network and knowledge maps for the novel crisis of coronavirus (COVID-19) pandemic. During a pandemic, identifying the fields of scientific study that have attracted greater research attention with the pandemic is of paramount importance in managing the pandemic. This paper aims to identify a number of popular subjects of research related to COVID-19 through topic modeling, as well as to demonstrate the role of information systems (IS) to raise awareness of new research. In this context, a corpus of 7,395 English articles related to COVID-19 published in the Web of Science database was analyzed by using the Latent Dirichlet Allocation (LDA) and the topics were identified, which are classified into five main themes: epidemiological studies, clinical studies, global impacts of COVID-19, guidelines regarding the challenges of COVID-19, and the role of information systems to manage the COVID-19 outbreak. The findings suggest that epidemiological and clinical studies are the core research topics in this respect, in line with the findings of a number of previous studies, while global impacts of COVID-19, guidelines regarding the challenges of COVID-19, and use of information systems in COVID-19 pandemic are new trend topics of COVID-19 research.
\end{abstract}

\section{KEYWORDS}

COVID-19, Topic Modeling, LDA, Research Trends, Information Systems

\section{INTRODUCTION}

The World Health Organization (WHO) announced the COVID-19 as a global pandemic on March 11, 2020 (WHO, 2020a). Earlier in this year, on January 11, the first deadly case due to coronavirus was reported in China (WHO, 2020a). Although the city of Wuhan was quarantined soon afterwards, the virus had already begun spreading to other countries exponentially by January 23 (Taylor, 2020). The distribution of the total COVID-19 cases, deaths and new cases in the past 24 hours by region as of August 10,2020 are presented in Table 1. There were 19,718,030 cases and 728,013 deaths globally(WHO, 2020b). COVID-19 has received huge attention in recent months because it has been affecting millions of people all around the world (Tran et al., 2020).It has significant impacts on security, politics, economy, society or technology(Etyang, 2020).

Table 1. Total cases, deaths, and new cases and deaths in the past 24 hours as of August 10, 2020 (WHO, 2020b)

\begin{tabular}{|l|c|c|l|c|}
\hline & Total cases & New cases in the past 24 hrs. & Total deaths & New deaths in the past 24 hrs. \\
\hline Globally & $19,718,030$ & 253,409 & 728,013 & 5,719 \\
\hline Africa & 895,696 & 10,706 & 16,713 & 310 \\
\hline Americas & $10,590,929$ & 143,668 & 388,673 & 3,597 \\
\hline Eastern Mediterranean & $1,644,359$ & 9,419 & 43,433 & 353 \\
\hline Europe & $3,582,911$ & 17,627 & 216,693 & 258 \\
\hline South-East Asia & $2,632,773$ & 66,973 & 53,677 & 1,108 \\
\hline Western Pacific & 370,621 & 5,016 & 8,811 & 93 \\
\hline
\end{tabular}

Due to its recent emergence as an infectious disease, COVID-19 is a currently popular research subject (Xiang et al., 2020). In the absence of vaccines and antiviral care, a good number of laboratories, researchers and corporations have been working to find a medication or vaccine for the treatment of COVID-19 (Haleem et al., 2020). There are other researchers who have been investigating the impacts of COVID-19 in social, 
economic, health-related and many other domains. Naturally, the number of academic studies in many fields have significantly increased over time (Tran et al., 2020). According to Dimensions (2020), while the number of clinical trials focusing of COVID-19 was 60 in the first week of January 2020, this number was 5,516 by the end of August, 2020 and there were 96,449 articles and 25,012 preprints. 7,395 articles in English became available in the Web of Science database until August 2020. On February 11-12, 2020, large number of scientists were brought together by the WHO in Geneva, and an R\&D Blueprint was created to provide ideas on COVID-19-related issues (WHO, 2020c). The R\&D Blueprint facilitates communication between scientists and has two main purposes: to find solutions that would slow the progression of the epidemic and a cure, and to support global research platforms against a new pandemic that may occur afterwards (WHO, 2020c). The WHO has also created a database where it collects international findings and information related to COVID-19. This regularly updated database has become a comprehensive resource for those who want to work on COVID-19 (WHO, 2020c). Scientific studies are of paramount importance in reducing the impacts of COVID-19 and preparing for a possible new pandemic (Tran et al., 2020). Identifying and studying the academic research about COVID-19 is, therefore, an urgent need (Haleem et al., 2020).

This paper aims to classify the current research topics related to COVID-19 and to illustrate the role of information systems based on a corpus of articles published in English through a systematic literature review in the Web of Science database. The paper reveals the research foci related to COVID-19 to increase the visibility of new research by using the Latent Dirichlet Allocation (LDA). In the next section, we briefly discuss some areas adversely affected by COVID-19 and section 3 describes the methodology used and provides some information about the topic modeling and LDA. Section 4 presents our findings and interpretations of the results. The final section is the conclusion section.

\section{LITERATURE REVIEW}

COVID-19 has a remarkable influence on individuals' daily life and routine of corporations. COVID-19 is considered a disease that has primarily affected the healthcare sector, but it has also harmed many other sectors. The COVID-19 outbreak has caused long-standing damage to the economy, education, and tourism and aviation. The potential impacts have prompted researchers to work on longer-term effects of the spread and to determine the dynamics of COVID-19.

The health sector has been heavily disrupted due to COVID-19. A rapid rise in the number of patients has caused a shortage of equipment, beds and personnel leading to healthcare systems' collapsing (Etyang, 2020). Some researchers concentrate on the treatment and diagnosis of COVID-19 (Gautret et al., 2020; X. Li et al., 2020; Tang et al., 2020). There are also studies focusing on the healthcare infrastructures of different countries (Etyang, 2020; Paintsil, 2020). These studies examine how prepared countries are against such a patient overload. Healthcare professionals are at the forefront and they directly communicate with COVID-19 patients; hence, psychological disorders and mental problems might occur. Moreover, a large number of cases, excessive workload, shortage of certain medications and lack of protective equipment might negatively affect healthcare workers (Lai et al., 2020; Chew et al., 2020). Several research studies have been conducted to integrate new technologies into the healthcare sector and use them in COVID-19 treatments in order to reduce the risks threatening healthcare workers and to provide an uninterrupted supply of medications (Bamber \& Fernandez-Stark, 2020; Javaid et al., 2020).

There are many studies on how the manufacturing of products has slowed down and the supply has been disrupted(Govindan et al., 2020; Reardon et al., 2020; Rizou et al., 2020). Economic harm both at the micro and macro levels is emphasized in the literature. United Nations Industrial Development Organization (UNIDO) points out that countries were severely affected by COVID-19 between December 2019 and April 2020, regardless of income level (UNIDO, 2020).

Additionally, some researchers focus on the volatility in the revenue growth (Atkeson, 2020; Fernandes, 2020; McKibbin \& Fernando, 2020; Usman et al., 2020) and there are studies analyzing the stock market reactions in the literature (Baker et al., 2020; Huo \& Qiu, 2020; Khanthavit, 2020; Zhang et al., 2020). According to the OECD data, while the unemployment rate was 5.2\% in February 2020 , this rate was $8.4 \%$ in May 2020 that is the highest unemployment rate in a decade. Moreover, in the fourth quarter of 2020, this rate is estimated to reach $9.4 \%$ (OECD, 2020). 
Most of the governments have temporarily closed their educational institutions to prevent the spread of COVID-19. UNESCO stated that as of March 4, 2020, schools were closed in 22 countries (UNESCO, 2020a). Sixty percent of the student population in the world has been affected by these closures (UNESCO, 2020b). Many countries' education systems have sustained their operations by shifting from traditional learning to digital learning. This unexpected transition to digital education is also studied in the literature (Barnes, 2020; Özer, 2020; Teräs et al., 2020). Furthermore, there are many studies focusing on the mental health of students during an epidemic (Cao et al., 2020; Li \& Leung, 2020; Zhai \& Du, 2020).

Many countries suffer from the disruption of tourism activities, vacation travel and passenger transportation. According to the data of UNWTO, international tourism shrank by $22 \%$ in the first quarter of the year, and this number is anticipated to reach $60-80 \%$ over the year (UNWTO, 2020). In this context, passenger mobility at airports worldwide declined by $12 \%$ in the first quarter of 2020 (ACI, 2020). The International Air Transport Association (2020) announced that the sector's revenue loss might reach 314 billion dollars (IATA, 2020). Most of the studies in this area analyze the impacts of the pandemic on cruises, air travel and accommodations (Farzanegan et al., 2020; Türker, 2020). Researchers also examine how much damage COVID-19 has caused to domestic and international aviation industry (Akipinar \& Seckin Codal, 2020; Çora, 2020; Macit, 2020).

Information systems have a crucial role in countering the COVID-19 pandemic by radically changing the dynamics of sectors, such as healthcare, education, businesses and etc., in addition to providing effective communication. Various information system strategies have been adopted by different countries in dealing with COVID-19 (C. Liu, 2020). With many people in lockdown, thousands of people dying, businesses going bankrupt, and many sectors and organizations suffering, several countries have imposed restrictions to prevent the spread of the disease. Researchers in different disciplines have cooperated against the challenges of COVID-19, and information systems scholars have also been making a great effort to fight COVID-19 (Ågerfalk et al., 2020). IS scholars have contributed new knowledge to the existing literature and proposed new areas for IS research that can be alternative solutions for such challenges (Pan \& Zhang, 2020). Research on IS is grouped under three main headings: diffusion and adoption of new technology, technology adaptation and tackling with the problems of technology use, impact of technology on well-being during the COVID-19 pandemic (Dey et al., 2020).

\section{METHODOLOGY}

We specifically address the following question in our study: What topics has research focused on in the scientific literature on COVID-19? For an answer to this question, firstly we collected the articles related to COVID-19 in the Web of Science database. The search was made with the keyword "COVID-19" and the document type was specified as articles are preferred. No category restrictions were applied while searching. Our data covers the period from December 2019 to August 2020. The article abstracts were exported to an Excel sheet. Non-English articles were not included in the analysis. Finally, the number of data entries for analysis was 7,395.

The second step was the data cleaning and preparation step to make the analysis easier and ensure we get more accurate results. The Excel sheet was converted to a csv file to make it more suitable for Pandas, a library in Python. All letters were converted to lowercase. All stop words were removed thanks to NLTK, the text-processing library of Python. Biagrams and trigrams were created. Python's Gensim library was imported and the functions corpora, simple_preprocess and CoherenceModel were run. While the tokenization was done through Gensim's function simple preprocess, lemmatization was analyzed by spacy's NLP library. A dictionary was created by Gensim's function corpora.Dictionary. The articles were finally converted into a document corpus via the function doc2bow to analyze distribution of semantic word clusters, i.e. the topic modeling. The flow diagram of LDA's preprocessing steps is presented in Figure 1. 


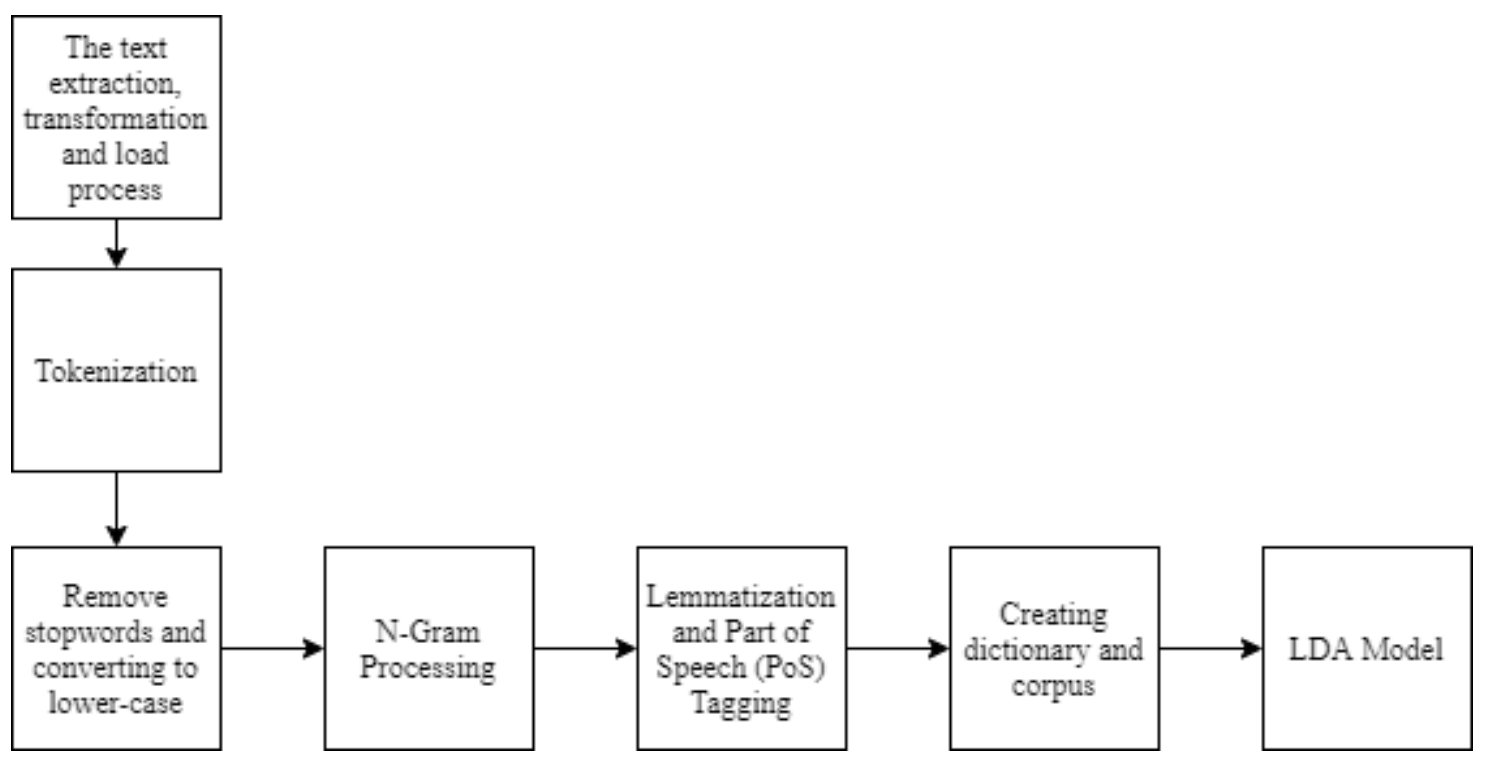

Figure 1. The preprocessing step for LDA

In this study, the topic modeling method was used to determine what topics have been focused on in the scientific literature on COVID-19. LDA was preferred because it is the most well-known topic modeling method (Habibabadi \& Haghighi, 2019).Unsupervised machine learning algorithms and probabilistic topic models are utilized by researchers to extract hidden information from various text automatically. LDA, one of the probabilistic topic models, shows great performance in the fields of information retrieval, text classifications and text annotations (Bellegarda, 2008; Blei, 2012; Z. Liu, 2013). The main logic of LDA is that documents are symbolized as random mixtures over latent topics, and every topic is qualified by a distribution over words (Jordan et al., 2003). Compared to other probabilistic models, LDA is advantageous as it trains models directly with mature probability algorithms, it is more stable than non-hierarchical models and it provides better semantic conditions and a stronger descriptive power (Girolami \& Kabán, 2003; Z. Liu, 2013). Additionally, since LDA's logic is based on the probability distribution of topics, it eases the generative process and efficiently works on large-scale datasets (Z. Liu, 2013; Masada et al., 2008). Chen and colleagues (2020) have studied an effective model for forecasting preoperative critical disease with the help of LDA. LDA is a commonly applied method to determine customer profiles and retrieve information from customer comments in marketing areas (H. Li, 2020; Sutherland et al., 2020). Moreover, it is beneficial to identify hot topics on specific issues on social media (Abd-Alrazaq et al., 2020; Xue et al., 2020). Mori and colleagues (2020) propose an automated evaluation system for improving working skills by using LDA. Y. Liu and Cheng (2020) reveal the transit patterns using the LDA technique on personalized smart card data. They understand passenger behaviors by interpreting these inferences with geodemographics data.

LDA Mallet is used in this study. "MALLET is a Java-based package for statistical natural language processing, document classification, clustering, topic modeling, information extraction, and other machine learning applications to text" (Mallet, 2020). The MALLET package contains an highly scalable and fast implementation of Gibbs sampling. For the second part of the analysis, we tried a few numbers of topics to determine the best number by using the CoherenceModel package. We compared the coherence scores for four different numbers of topics: $5,10,15$, and 20 . The best score was yielded by 10 , which was then adopted as the number of topics. Then, the topics were labeled with the help of opinions of three researchers. A consistency analysis was performed across the opinions of the researchers.

\section{RESULTS AND DISCUSSION}

This paper contributes to the literature by specifying the current research foci related to COVID-19, illuminating some crucial gaps that previous studies have not addressed. Previous studies about COVID-19 literature have generally concentrated on bibliometric analysis (Verma \& Gustafsson, 2020). In our study, using the topic modeling method, we examine the current literature not only on the basis of text, but also with its semantic structure. The current study reveals a shift in the topics of COVID-19 publications and contributes 
to determining the current topic subjects. We used the 7,395 articles we found in the Web of Science database, and applied LDA only for the abstracts of these articles in Python. Based on the fact that the highest coherence score was obtained with 10 topics, the most appropriate labels were defined for the 10 topics by help of three independent researchers. A list of the ten research topics related to COVID-19 and their respective top ten most frequent words are presented in Table 3.

Table 3. Ten research topics related to COVID-19 and their respective top ten most frequent words

\begin{tabular}{|c|c|}
\hline Topic & Top Ten Most Frequent Words \\
\hline 1.Epidemiological situation of COVID-19 & $\begin{array}{l}\text { case, number, measure, control, epidemic, rate, model, transmission, } \\
\text { country, spread }\end{array}$ \\
\hline $\begin{array}{l}\text { 2. COVID-19 impacts on mental health and } \\
\text { psychological well-being }\end{array}$ & covid, health, study, risk, level, high, factor, result, survey, mental \\
\hline $\begin{array}{l}\text { 3. COVID-19 research for the progress of } \\
\text { diagnostic values }\end{array}$ & result, test, method, study, covid, base, positive, datum, model, perform \\
\hline $\begin{array}{l}\text { 4. Laboratory and clinical examination on patients } \\
\text { admitted to the hospital }\end{array}$ & $\begin{array}{l}\text { patient, covid, infection, symptom, disease, case, report, present, clinical, } \\
\text { severe }\end{array}$ \\
\hline 5. Prevention of the COVID-19 & virus, viral, potential, drug, human, cell, target, treatment, infection, study \\
\hline $\begin{array}{l}\text { 6. The global impact of COVID-19 on the socio- } \\
\text { economic status }\end{array}$ & $\begin{array}{l}\text { pandemic, crisis, impact, social, policy, world, paper, economic, global, } \\
\text { change }\end{array}$ \\
\hline $\begin{array}{l}\text { 7. Developing an emergency risk management plan } \\
\text { for health-care organizations }\end{array}$ & $\begin{array}{l}\text { care, patient, risk, management, medical, hospital, covid, emergency, } \\
\text { pandemic, procedure }\end{array}$ \\
\hline $\begin{array}{l}\text { 8. Supportive advice for coping with the pandemic- } \\
\text { related challenges }\end{array}$ & $\begin{array}{l}\text { pandemic, challenge, experience, support, work, provide, face, practice, } \\
\text { service, research }\end{array}$ \\
\hline 9. The role of IS to manage the COVID-19 outbreak & $\begin{array}{l}\text { health, public, covid, response, information, system, strategy, global, } \\
\text { provide, spread }\end{array}$ \\
\hline 10. Risk stratification of COVID-19 cases & patient, group, clinical, severe, age, high, day, study, year, compare \\
\hline
\end{tabular}

The topics listed in Table 3 can be divided into five categories: epidemiological studies (Topic 1), clinical studies (Topic 3, 4, 5, 10), global impacts of COVID-19 (Topic 2, 6), guidelines regarding the challenges of COVID-19 (Topic 7, 8), and the role of information systems to manage the COVID-19 pandemic (Topic 9). Our findings are in line with previous LDA studies, which demonstrate that epidemiological and clinical studies are core research foci (Tran et al., 2020).

Some researchers work on faster and more accurate methods for the diagnosis, treatment and control of the spread of the virus (Jiao et al., 2020; Sheikhzadeh et al., 2020). COVID-19 causes medical problems of different clinical severities, manifesting with both extra-respiratory and respiratory symptoms. There are studies examining how manifestations vary between severe and non-severe COVID-19 cases in terms of nature and frequency, to help researchers specify a treatment method and determine high-risk patient groups (Bao et al., 2020; Dalal et al., 2020). Besides the clinical aspects of COVID-19, some researchers actively work on the whole range of short-term and long-term impacts of COVID-19. They intensely study how people have been affected in economic, social and psychological terms and make suggestions to reduce the negative impacts of the crisis (Choudhari, 2020; Song, 2020; Vindegaard \& Eriksen Benros, 2020). A group of researchers investigate the relationship between possible impacts of the pandemic on mental health and socio-demographic factors. Healthcare workers who are at the forefront of combating the pandemic, students who have undergone academic disruptions, and workers who lost their jobs are frequently chosen as subjects in research (Cao et al., 2020; Greenberg et al., 2020; Lai et al., 2020). Since there is still little known about COVID-19, the WHO and many countries have been publishing many informative articles for the public and healthcare professionals. The WHO has determined the major themes of informative articles: public guidance, national healthcare systems and technical consulting, situation updates, research and development, and scam alerts. The WHO has also published its COVID-19 Emergency Use Listing Procedure and generated a COVID-database that gathers the academic research related to COVID-19 (WHO | World Health Organization, 2020).

A topic determined in this study which is different from those of previous studies is the role of IS to manage the COVID-19 outbreak. Information systems have a crucial role in responding to COVID-19; hence, IS 
scholars concentrate on the existing literature to create a new approach to tackle the challenges of COVID-19 (Pan \& Zhang, 2020). The struggle with pandemic has been gradually more dependent on technology and information systems.

Some researchers focus on the adoption and adaptation of new technological applications, such as new social media-based applications, video and voice call software, etc. (Dey et al., 2020). Some video meeting applications have rapidly become widespread and moved beyond social and national borders. Many industries now operate their businesses remotely by means of such platforms (Barnes, 2020). A number of governments have ordered to continue education by shifting from traditional learning to digital learning due to the school closures (Özer, 2020). Web conferencing systems and digital monitoring are also used to provide patients with remote healthcare (Whitelaw et al., 2020). Moreover, AI methods enable more rapid diagnosis. Images can be processed in seconds and results differentiated from the manifestations of other lung diseases; hence, diagnosis times substantially decline with AI methods (McCall, 2020). Many governments have integrated digital technologies into their pandemic policies to perform planning, testing, surveillance, quarantine, contact tracing and clinical management in order to reduce COVID-19 cases and deaths. The people are tracked by using facial recognition technology, security cameras, global positioning systems (GPS) and bank card records (Fisher \& Sang-Hun, 2020). In Singapore, the distance between any two individuals is determined by Singapore Ministry of Health via a mobile phone application called UpCode using Bluetooth signals. Moreover, UpCode is also used to estimate the tendency for COVID-19 cases to infect others by sex, age, location and recovery time (Dick, 2020). In Germany, a smartwatch application provides useful data for individual temperatures, sleep patterns and pulses (Busvine, 2020). The Turkish Ministry of Health has launched the application "Hayat Eve Sığar" to identify recent physical contacts of infected persons with a HesCode (Sağlık Bakanlığ 1,2020$)$. In China, people are tracked through migration maps. Migration maps collect real time data from mobile phones, social media and mobile payment applications (Hu et al., 2020). The Taiwan government requires health checks for airline travelers by using the national health insurance database and individual migration records (Wang et al., 2020). Sweden authorities have announced a platform to track the number of COVID-19 patients, protective healthcare equipment, hospital bed capacity, and other resources (Drees, 2020).

\section{CONCLUSION}

This study analyzed, through the LDA method, English manuscripts submitted during and related to the Covid-19 pandemic as available crisis in the Web of Science database. In this paper, the high-priority research landscape of the COVID-19 publications is outlined and the importance of information systems in this respect is highlighted. The topics determined through LDA are as follows: epidemiological situation of COVID-19, COVID-19 impacts on mental health and psychological well-being, COVID-19 research for the progress of diagnostic values, laboratory and clinical examination on patients admitted to the hospital, prevention of the COVID-19, the global impact of COVID-19 on the socio-economic status, developing an emergency risk management plan for health-care organizations, supportive advice for coping with the pandemic-related challenges, the role of IS to manage the COVID-19 outbreak and risk stratification of COVID-19 cases. The role of information systems to manage the COVID-19 outbreak is a revolutionary new trend to tackling the pandemic. This study contributes to the determination of current topics and it could inspire researchers in the process of identifying the topics of new research and potential directions for future work.

The analysis was conducted by searching the Web of Science with the keyword "COVID-19", and the LDA method was applied to the abstracts of the articles retrieved because the abstract of an article provides a powerful statement, including the scope, purpose, results, and contents of the work while the rest of the article provides comprehensive information. The only language preferred for searching the articles was English, which introduces a challenge for examining other studies written in different languages. For further studies, the methodology used in this study to analyze COVID-19 research can be progressively improved, using different databases, greater number of keywords, and more advanced text mining techniques.

\section{REFERENCES}

Abd-Alrazaq, A., Alhuwail, D., Househ, M., Hamdi, M., \& Shah, Z. (2020). Top Concerns of Tweeters During the COVID-19 Pandemic: Infoveillance Study. Journal of Medical Internet Research, 22(4), e19016. https://doi.org/10.2196/19016

ACI. (2020). The impact of COVID-19 on the airport business: preliminary assessment. 
Ågerfalk, P. J., Conboy, K., \& Myers, M. D. (2020). Information systems in the age of pandemics: COVID-19 and beyond. European Journal of Information Systems, 29(3), 203-207. https://doi.org/10.1080/0960085X.2020.1771968

Akipinar, M. T., \& Seckin Codal, K. (2020). The Impact of the Coronavirus (COVID-19) Outbreak on Asia-Pacific Airways Stocks Prices : An Event-Study Approach. 2.

Atkeson, A. (2020). What Will Be the Economic Impact of COVID-19 in the US? Rough Estimates of Disease Scenarios. In NBER Working Paper Series (Issue 595, p. 25). https://doi.org/10.3386/w26867

Baker, S., Bloom, N., Davis, S., Kost, K., Sammon, M., \& Viratyosin, T. (2020). The Unprecedented Stock Market Impact of COVID-19. National Bureau of Economic Research. https://doi.org/10.3386/w26945

Bamber, P., \& Fernandez-Stark, K. (2020). Why global value chains remain essential for COVID-19 supplies. https://www.researchgate.net/publication/343190696

Barnes, S. J. (2020). Information management research and practice in the post-COVID-19 world. International Journal of Information Management, 102175. https://doi.org/10.1016/j.ijinfomgt.2020.102175

Bellegarda, J. R. (2008). Latent Semantic Mapping: Principles \& Applications. San Rafael: Morgan and Claypool Publishers.

Blei, D. M. (2012). Probabilistic topic models. Communications of the Acm, 55(4).

Busvine, D. (2020). Germany launches smartwatch app to monitor coronavirus spread | Reuters. https://www.reuters.com/article/us-health-coronavirus-germany-tech-idUSKBN21P1SS

Cao, W., Fang, Z., Hou, G., Han, M., Xu, X., Dong, J., \& Zheng, J. (2020). The psychological impact of the COVID-19 epidemic on college students in China. Psychiatry Research, 287. https://doi.org/10.1016/j.psychres.2020.112934

Chen, Y., Zhang, L., Zhang, J., Yi, B., \& Qin, X. (2020). PREOPERATIVE RISK PREDICTION OF HEART FAILUREWITH NUMERICAL AND TEXTUAL ATTRIBUTES. International Journal of InnovativeComputing, Information and Control, 16(6).

Chew, N. W. S., Lee, G. K. H., Tan, B. Y. Q., Jing, M., Goh, Y., Ngiam, N. J. H., Yeo, L. L. L., Ahmad, A., Ahmed Khan, F., Napolean Shanmugam, G., Sharma, A. K., Komalkumar, R. N., Meenakshi, P. V., Shah, K., Patel, B., Chan, B. P. L., Sunny, S., Chandra, B., Ong, J. J. Y., ... Sharma, V. K. (2020). A multinational, multicentre study on the psychological outcomes and associated physical symptoms amongst healthcare workers during COVID-19 outbreak. Brain, Behavior, and Immunity, 88, 559-565. https://doi.org/10.1016/j.bbi.2020.04.049

Çora, H. (2020). IMPACT OF COVID-19 ON GLOBAL AND TURKISH AVIATION SECTOR - PROACTIVE AND PREEMPTIVE MEASURES DURING AND AFTER PANDEMIC. International Journal of Advanced Science and Technology, 29(8), 2825-2851.

Dey, B. L., Al-Karaghouli, W., \& Muhammad, S. S. (2020). Adoption, Adaptation, Use and Impact of Information Systems during Pandemic Time and Beyond: Research and Managerial Implications. Information Systems Management. https://doi.org/10.1080/10580530.2020.1820632

Dick, S. (2020). Singapore's COVID-19 temperature scans and tracking leading the way. https://thenewdaily.com.au/news/national/2020/03/19/singapore-coronavirus-temperature-scans/

Dimensions. (2020). COVID19| Dimensions. https://www.dimensions.ai/covid19/

Drees, J. (2020). Swedish Health Services taps Microsoft to build app that tracks COVID-19 patients, hospital capacity. https://www.beckershospitalreview.com/healthcare-information-technology/swedish-health-services-taps-microsoftto-build-app-that-tracks-covid-19-patients-hospital-capacity.html

Elmer, T., Mepham, K., \& Stadtfeld, C. (2020). Students under lockdown: Comparisons of students' social networks and mental health before and during the COVID-19 crisis in Switzerland. PLOS ONE, 15(7), e0236337. https://doi.org/10.1371/journal.pone.0236337

Etyang, O. (2020). COVID-19 Pandemic and its Potential Impact on The Health Sector in the COMESA Region. https://au.int/sites/default/files/documents/38326-doc-cov-

Farzanegan, M. R., Gholipour, H. F., Feizi, M., Nunkoo, R., \& Andargoli, A. E. (2020). International Tourism and Outbreak of Coronavirus (COVID-19): A Cross-Country Analysis. In Journal of Travel Research. SAGE Publications Ltd. https://doi.org/10.1177/0047287520931593

Fernandes, N. (2020). Economic Effects of Coronavirus Outbreak (COVID-19) on the World Economy. SSRN Electronic Journal. https://doi.org/10.2139/ssrn.3557504

Fisher, M., \& Sang-Hun, C. (2020). How South Korea Flattened the Coronavirus Curve. The New York Times. https://www.nytimes.com/2020/03/23/world/asia/coronavirus-south-korea-flatten-curve.html

Gautret, P., Lagier, J. C., Parola, P., Hoang, V. T., Meddeb, L., Mailhe, M., Doudier, B., Courjon, J., Giordanengo, V., Vieira, V. E., Tissot Dupont, H., Honoré, S., Colson, P., Chabrière, E., La Scola, B., Rolain, J. M., Brouqui, P., \& Raoult, D. (2020). Hydroxychloroquine and azithromycin as a treatment of COVID-19: results of an open-label non-randomized clinical trial. International Journal of Antimicrobial Agents, 56(1). https://doi.org/10.1016/j.ijantimicag.2020.105949

Girolami, M., \& Kabán, A. (2003). On an equivalence between PLSI and LDA. 26th Annual International ACM SIGIR Conference on Research and Development in Informaion Retrieval, 433-434.

Gössling, S., Scott, D., \& Hall, C. M. (2020). Pandemics, tourism and global change: a rapid assessment of COVID-19. Journal of Sustainable Tourism, 1-20. https://doi.org/10.1080/09669582.2020.1758708 
Govindan, K., Mina, H., \& Alavi, B. (2020). A decision support system for demand management in healthcare supply chains considering the epidemic outbreaks: A case study of coronavirus disease 2019 (COVID-19). Transportation Research Part E: Logistics and Transportation Review, 138, 101967. https://doi.org/10.1016/j.tre.2020.101967

Greenberg, N., Docherty, M., Gnanapragasam, S., \& Wessely, S. (2020). Managing mental health challenges faced by healthcare workers during covid-19 pandemic. https://doi.org/10.1136/bmj.m1211

Habibabadi, S. K., \& Haghighi, P. D. (2019). Topic Modelling for Identification of Vaccine Reactions in Twitter. ACM International Conference Proceeding Series, 1-10. https://doi.org/10.1145/3290688.3290735

Haleem, A., Javaid, M., Vaishya, R., \& Deshmukh, S. G. (2020). Areas of academic research with the impact of COVID-19. In American Journal of Emergency Medicine (Vol. 38, Issue 7, pp. 1524-1526). W.B. Saunders. https://doi.org/10.1016/j.ajem.2020.04.022

Hu, Z., Ge, Q., Li, S., Jin, L., \& Xiong, M. (2020). Artificial Intelligence Forecasting of Covid-19 in China. http://arxiv.org/abs/2002.07112

Huo, X., \& Qiu, Z. (2020). How does China's stock market react to the announcement of the COVID-19 pandemic lockdown? Economic and Political Studies, 1-26. https://doi.org/10.1080/20954816.2020.1780695

IATA. (2020). IATA - Home. https://www.iata.org/

Javaid, M., Haleem, A., Vaishya, R., Bahl, S., Suman, R., \& Vaish, A. (2020). Industry 4.0 technologies and their applications in fighting COVID-19 pandemic. Diabetes and Metabolic Syndrome: Clinical Research and Reviews, 14(4), 419-422. https://doi.org/10.1016/j.dsx.2020.04.032

Jiao, J., Duan, C., Xue, L., Liu, Y., Sun, W., \& Xiang, Y. (2020). DNA nanoscaffold-based SARS-CoV-2 detection for COVID-19 diagnosis. Biosensors and Bioelectronics, 167. https://doi.org/10.1016/j.bios.2020.112479

Jordan, M., Blei, D. M., Ng, A. Y., \& Edu, J. B. (2003). Latent Dirichlet Allocation Sampling and Bayesian inference View project EM and optimization algorithms in statistical models View project Latent Dirichlet Allocation Michael I. Jordan. In Journal of Machine Learning Research (Vol. 3). https://www.researchgate.net/publication/221620547

Khanthavit, A. (2020). World and National Stock Market Reactions to COVID-19. https://doi.org/10.13140/RG.2.2.22792.57606

Lai, J., Ma, S., Wang, Y., Cai, Z., Hu, J., Wei, N., Wu, J., Du, H., Chen, T., Li, R., Tan, H., Kang, L., Yao, L., Huang, M., Wang, H., Wang, G., Liu, Z., \& Hu, S. (2020). Factors Associated With Mental Health Outcomes Among Health Care Workers Exposed to Coronavirus Disease 2019. JAMA Network Open, 3(3), e203976. https://doi.org/10.1001/jamanetworkopen.2020.3976

Li, H. (2020). Charting the Path to Purchase UsingTopic Models. Journal of Marketing Research, 57(6), 1019-1036.

Li, T. M. H., \& Leung, C. S. Y. (2020). Exploring student mental health and intention to use online counseling in Hong Kong during the COVID-19 pandemic. In Psychiatry and Clinical Neurosciences. Blackwell Publishing. https://doi.org/10.1111/pcn.13117

Li, X., Geng, M., Peng, Y., Meng, L., \& Lu, S. (2020). Molecular immune pathogenesis and diagnosis of COVID-19. In Journal of Pharmaceutical Analysis (Vol. 10, Issue 2, pp. 102-108). Xi'an Jiaotong University. https://doi.org/10.1016/j.jpha.2020.03.001

Liu, C. (2020). Health information systems amid COVID-19 outbreak: Lessons from China. Health Information Management Journal. https://doi.org/10.1177/1833358320947557

Liu, Y., \& Cheng, T. (2020). Understanding public transit patterns with open geodemographics to facilitate public transport planning. Transportmetrica A: Transport Science, 16(1), 76-103. https://doi.org/10.1080/23249935.2018.1493549

Liu, Z. (2013). High Performance Latent Dirichlet Allocation for Text Mining. September.

Macit, A. M. D. (2020). Türk Sivil Havactlı Sektöründe Covid-19 Pandemisinin Yönetimi. https://www.researchgate.net/publication/341327367_Turk_Sivil_Havacilik_Sektorunde_Covid19_Pandemisinin_Yonetimi

Mallet. (2020). MALLET homepage. http://mallet.cs.umass.edu/

Masada, T., Kiyasu, S., \& Miyahara, S. (2008). Comparing LDA with pLSI as a dimensionality reduction method in document clustering. LKR'08 Proceedings of the 3rd International Conference on Large-Scale Knowledge Resources: Construction and Application, 13-26.

McCall, B. (2020). COVID-19 and artificial intelligence: protecting health-care workers and curbing the spread. The Lancet Digital Health, 2(4), e166-e167. https://doi.org/10.1016/s2589-7500(20)30054-6

McKibbin, W. J., \& Fernando, R. (2020). The Global Macroeconomic Impacts of COVID-19: Seven Scenarios. SSRN Electronic Journal. https://doi.org/10.2139/ssrn.3547729

Mori, K., Nakajima, H., \& Hata, Y. (2020). Automated worker skill evaluation for improving productivity based on labeled LDA. International Journal of Machine Learning and Cybernetics.

OECD. (2020). Tackling coronavirus (COVID-19) Contributing to a global effort. https://www.oecd.org/coronavirus/en/\#highlights

Özer, M. (2020). COVID-19 SALGINI SONRASI DÜNYADA EĞITIM. MEB. http://www.meb.gov.tr/covid-19-salginisonrasi-dunyada-egitim/haber/20936/tr 
Paintsil, E. (2020). COVID-19 threatens health systems in sub-Saharan Africa: The eye of the crocodile. In Journal of Clinical Investigation (Vol. 130, Issue 6, pp. 2741-2744). American Society for Clinical Investigation. https://doi.org/10.1172/JCI138493

Pan, S. L., \& Zhang, S. (2020). From fighting COVID-19 pandemic to tackling sustainable development goals: An opportunity for responsible information systems research. International Journal of Information Management, 55(June), 102196. https://doi.org/10.1016/j.ijinfomgt.2020.102196

Reardon, T., Bellemare, M. F., \& Zilberman, D. (2020). How COVID-19 may disrupt food supply chains in developing countries. IFPRI Book Chapters, 78-80. https://ideas.repec.org/h/fpr/ifpric/133821.html

Rizou, M., Galanakis, I. M., Aldawoud, T. M. S., \& Galanakis, C. M. (2020). Safety of foods, food supply chain and environment within the COVID-19 pandemic. In Trends in Food Science and Technology (Vol. 102, pp. 293-299). Elsevier Ltd. https://doi.org/10.1016/j.tifs.2020.06.008

Sağlık Bakanlığı. (2020). hayatevesığar. https://hayatevesigar.saglik.gov.tr/hes.html

Sheikhzadeh, E., Eissa, S., Ismail, A., \& Zourob, M. (2020). Diagnostic techniques for COVID-19 and new developments. In Talanta (Vol. 220). Elsevier B.V. https://doi.org/10.1016/j.talanta.2020.121392

Sutherland, I., Sim, Y., Lee, S. K., Byun, J., \& Kiatkawsin, K. (2020). Topic Modeling of Online Accommodation Reviews via Latent Dirichlet Allocation.

Tang, Y. W., Schmitz, J. E., Persing, D. H., \& Stratton, C. W. (2020). Laboratory diagnosis of COVID-19: Current issues and challenges. In Journal of Clinical Microbiology (Vol. 58, Issue 6). American Society for Microbiology. https://doi.org/10.1128/JCM.00512-20

Taylor, D. B. (2020). A Timeline of the Coronavirus Pandemic. The New York Times. https://www.nytimes.com/article/coronavirus-timeline.html

Teräs, M., Suoranta, J., Teräs, H., \& Curcher, M. (2020). Post-Covid-19 Education and Education Technology 'Solutionism': a Seller's Market. Postdigital Science and Education, 1-16. https://doi.org/10.1007/s42438-020-00164$\mathrm{x}$

Tran, B. X., Ha, G. H., Nguyen, L. H., Vu, G. T., Hoang, M. T., Le, H. T., Latkin, C. A., Ho, C. S. H., \& Ho, R. C. M. (2020). Studies of novel coronavirus disease 19 (Covid-19) pandemic: A global analysis of literature. International Journal of Environmental Research and Public Health, 17(11), 1-20. https://doi.org/10.3390/ijerph17114095

Türker, G. Ö. (2020). How Covid-19 pandemic affects tourism sector? An evaluation from tourism academics perspective. International Journal of Social Sciences and Education Research, 207-224. https://doi.org/10.24289/ijsser.760790

UNESCO. (2020a). 290 million students out of school due to COVID-19: UNESCO releases first global numbers and mobilizes response. https://en.unesco.org/news/290-million-students-out-school-due-covid-19-unesco-releases-firstglobal-numbers-and-mobilizes

UNESCO. (2020b). School closures caused by Coronavirus (Covid-19). https://en.unesco.org/covid19/educationresponse

UNIDO. (2020). Coronavirus: the economic impact - 10 July 2020| UNIDO. https://www.unido.org/stories/coronaviruseconomic-impact-10-july-2020

UNWTO. (2020). International Tourist Numbers Could Fall 60-80\% in 2020, UNWTO Reports | UNWTO. https://www.unwto.org/news/covid-19-international-tourist-numbers-could-fall-60-80-in-2020

Usman, M., Ali, Y., Riaz, A., Riaz, A., \& Zubair, A. (2020). Economic perspective of coronavirus (COVID-19). In Journal of Public Affairs. John Wiley and Sons Ltd. https://doi.org/10.1002/pa.2252

Verma, S., \& Gustafsson, A. (2020). Investigating the emerging COVID-19 research trends in the field of business and management: A bibliometric analysis approach. Journal of Business Research 118, January, 253-261.

Wang, C., NG, C., \& Brook, R. (2020). Response to COVID-19 in Taiwan. https://doi.org/10.1001/jama.2020.3151

Whitelaw, S., Mamas, M. A., Topol, E., \& Van Spall, H. G. C. (2020). Applications of digital technology in COVID-19 pandemic planning and response. The Lancet Digital Health, 2(8), e435-e440. https://doi.org/10.1016/S25897500(20)30142-4

WHO. (2020a). Archived: WHO Timeline - COVID-19. https://www.who.int/news-room/detail/27-04-2020-who-timeline--covid-19

WHO. (2020b). Coronavirus disease (COVID-19) Situation Report-203.

WHO. (2020c). R\&D Blueprint and COVID-19. https://www.who.int/teams/blueprint/covid-19

WHO | World Health Organization. (2020). https://www.who.int/

Xiang, Y. T., Li, W., Zhang, Q., Jin, Y., Rao, W. W., Zeng, L. N., Lok, G. K. I., Chow, I. H. I., Cheung, T., \& Hall, B. J. (2020). Timely research papers about COVID-19 in China. In The Lancet (Vol. 395, Issue 10225, pp. 684-685). Lancet Publishing Group. https://doi.org/10.1016/S0140-6736(20)30375-5

Xue, J., Chen, J., Chen, C., Zheng, C., Li, S., \& Zhu, T. (2020). Public discourse and sentiment during the COVID19 pandemic:Using Latent Dirichlet Allocation for topic modeling on Twitter. PLOS ONE, 15(9).

Zhai, Y., \& Du, X. (2020). Mental health care for international Chinese students affected by the COVID-19 outbreak. In The Lancet Psychiatry (Vol. 7, Issue 4, p. e22). Elsevier Ltd. https://doi.org/10.1016/S2215-0366(20)30089-4

Zhang, D., Hu, M., \& Ji, Q. (2020). Financial markets under the global pandemic of COVID-19. Finance Research Letters, 36, 101528. https://doi.org/10.1016/j.frl.2020.101528 